\title{
Parameters of Pre-Stressed Box Girder Bridge under Different Radius of Curvature
}

\author{
Dr Rajan Suwal \\ Department of Civil Engineering, \\ Institute of Engineering, Pulchowk Campus, \\ Lalitpur, Nepal \\ rajan_suwal@ioe.edu.np
}

\author{
Deepika Sharma \\ Civil Engineer, Ministry of Physical \\ Infrastructure Development, Bagmati \\ Province,Nepal
}

\begin{abstract}
This research, it is primarily intended to assess parametric study of pre-stressed Box-Girder bridges. Radius of Curvature was varied in $50 \mathrm{~m}$ span bridge in horizontal direction only. All the models are subjected to self-weight and moving load of IRC class 70R vehicle [3]. For this research, a three dimensional finite element (FE) model of two lane simply supported Box Girder Bridge made up of pre-stressed concrete has been developed using commercial software SAP 2000 version 14.0. Modal analysis has been carried out to obtain the mode shapes and various vibration properties such as fundamental time period and frequencies. For acceleration time history analysis Gorkha Earthquake has been used. From modal analysis the longitudinal stress at top and bottom of cross sections, bending moment, torsion, deflection and fundamental frequency are calculated. The responses of a curved bridges in comparison straight bridge are recorded. The ratio of responses is represented by a parameter. From the responses linear equation has been generated for torsion, bending moment, and deflection. Increase in Bending Moment, Torsion, deflection and stresses due to curvature can be represented by multiplication factor, ratio of maximum response of curved bridge to that of straight bridge from moving load analysis, within reasonable accuracy which can be used in preliminary design.
\end{abstract}

\section{Keywords}

Pre-stressed Box Girder Bridge, varying radius of curvature, FE model in SAP, simply supported, modal analysis, parametric study.

\section{INTRODUCTION}

Contemporary highway bridges are usually curved horizontally due to traffic load and agility, the geometric restriction of the metropolitan environment, and also due development of structural forms that enables curved construction. Despite all the advantages, the current specifications of IRC, no separate guideline for the curved bridge except consideration of torsion moment[8]. Curved structures were analyzed and designed as a series of straight segments [1]. Live load distribution was considered as whole-width design approach [2]. But some recent cases of poor bridge performance have made it clear that this approach has its limitations and new guidelines are required for their design. Nowadays higher level investigations are possible due to the high capacity computational systems available. It is required to examine these bridges using finite element analysis with different radius of curvatures configurations (i.e. closed box girders).

\section{METHODOLOGY}

\subsection{Modelling}

For this research, a three dimensional finite element (FE) model of two lane simply supported straight Box Girder Bridge made up of pre-stressed concrete has been developed using commercial software SAP 2000 version 14.0/Bridge.[7] The abutment is modeled using beam element supported on rigidly fixed foundation spring. [4][5]

\subsection{Parametric Variation}

A parametric study was conducted on the finite element model to study the response. Bending Moment, Torsion, Shear force, deflection and longitudinal stresses are observed.[6] Only Radius of Curvature has been varied. For parametric variation Aandhi Khola box girder situated at Syanga district has been taken as standard bridge. The bridge is straight bridge. The curvature has been introduced on the same bridge model while other material and geometric properties retain their original values during analysis. Responses of bridge are compared in terms of $\mathrm{L} / \mathrm{R}$ ratio.

Table 1: Span to curvature ratio

\begin{tabular}{|c|c|c|}
\hline \multicolumn{3}{|c|}{ Parameter: Radius of Curvature } \\
\hline Ranges & Span & (span/curvature)Ratio \\
\hline Straight & 50 & 0 \\
\hline 200 & 50 & 0.25 \\
\hline 175 & 50 & 0.28 \\
\hline 150 & 50 & 0.33 \\
\hline 125 & 50 & 0.4 \\
\hline 100 & 50 & 0.5 \\
\hline 70 & 50 & 0.71 \\
\hline 50 & 50 & 1 \\
\hline
\end{tabular}




\subsection{Time History Analysis}

A time history analysis is done on all bridge models using Gorkha Earthquake. Span of selected bridge is aligned along U1 direction (X direction). Since response of bridge is more severe when earthquake is applied along transverse direction, so North-South component of Earthquake ( $\mathrm{PGA}=0.17 \mathrm{~g}$ ) is applied along U2 (Ydirection). The output time steps for $(\mathrm{N}-\mathrm{S})$ were 0.005 seconds for a total time of $60 \mathrm{sec}$ with 12000. East- West component of earthquake $(\mathrm{PGA}=0.126 \mathrm{~g})$ is applied along $\mathrm{U} 1$ (X-direction). The output time steps were 0.005 seconds for $55 \mathrm{sec}$ with 11000 steps. The vertical component of Gorkha Earthquake $(\mathrm{PGA}=0.205 \mathrm{~g})$ is applied along vertical direction. The output time step for vertical analysis is $0.005 \mathrm{sec}$ with 13000 steps. The longitudinal stress at top and bottom of cross sections, bending moment, torsion, and deflection of a box girder curved in plan and straight are compared.

Accelerograms of Gorkha Earthquake is:

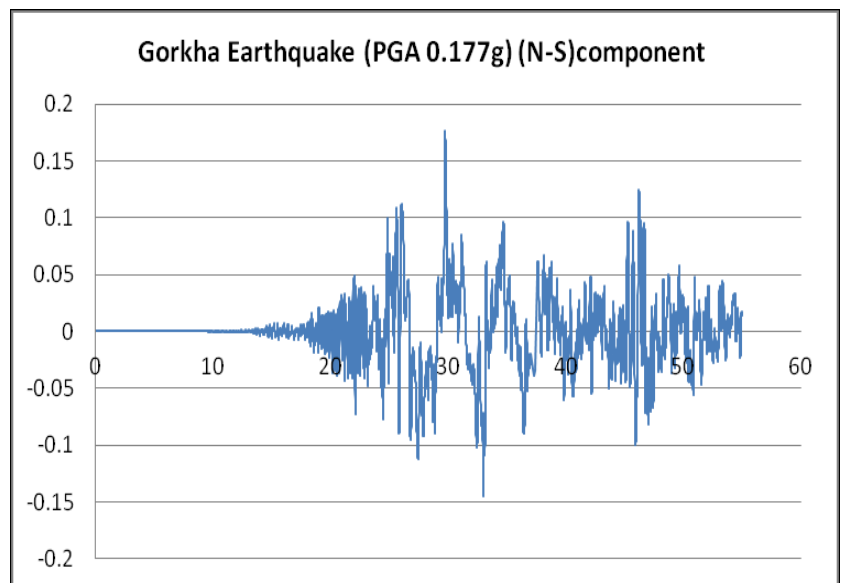

Figure 1: NS Component of Gorkha Earthquake

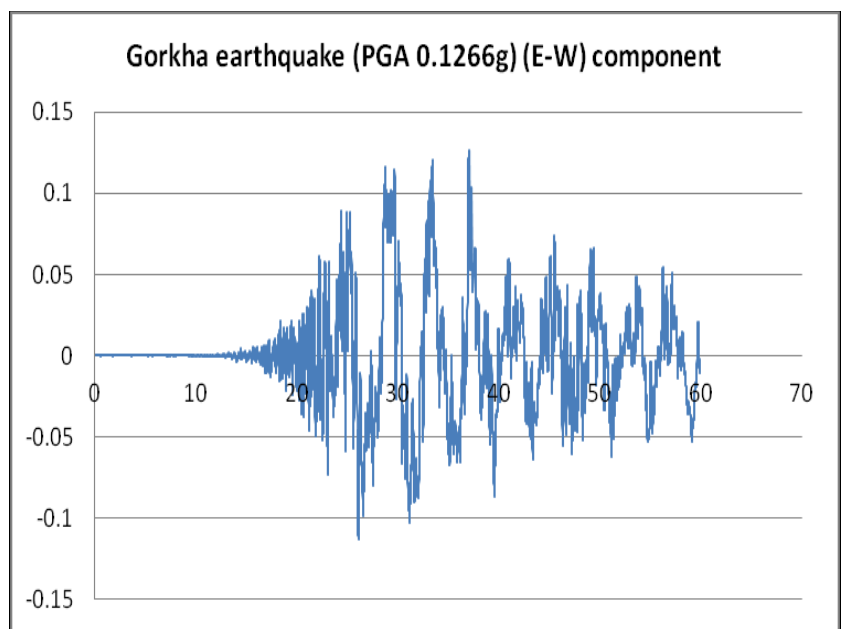

Figure 2: EW Component of Gorkha Earthquake

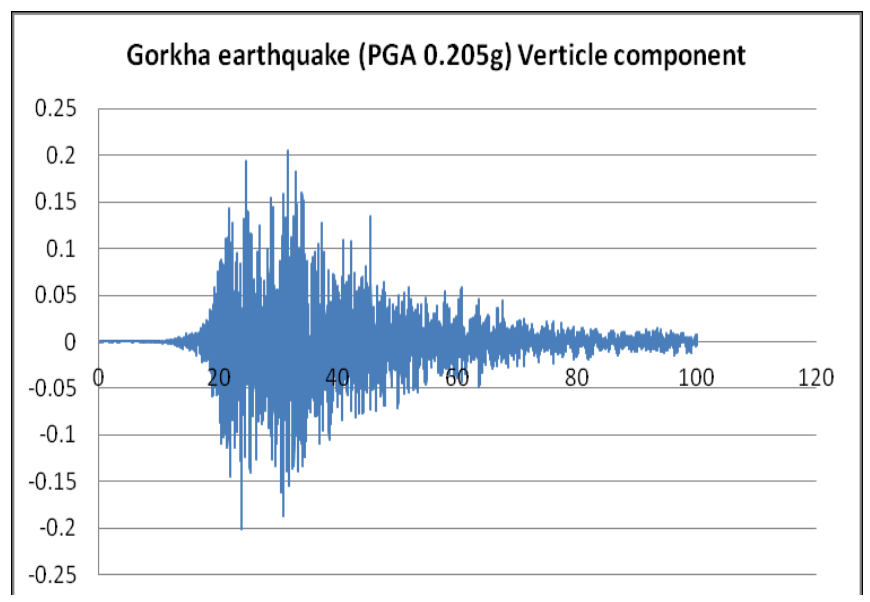

Figure 3: Verticle Component of Gorkha Earthquake

\section{RESULT AND DISCUSSION 3.1 Results of Static Analysis}

Analyses of the curved and straight box girder bridge models for dead load, pre-stressed load and moving load was conducted. Torsion, bending moment, longitudinal stress and deflections are monitored. The non-dimensional parameter (Span/Radius of Curvature) $(\mathrm{L} / \mathrm{R})$ is considered to plot the variation of the maximum responses of the bridges. Responses for the entire bridge model is considered under dead load pre-stressed load and moving load. The responses is plotted along the span of bridge. A non-dimensional parameter $\alpha$, is introduced here which represents ratio of maximum response of curved bridge to that of straight bridge from moving load analysis. The variation of responses represented by $\alpha$ is plotted against the non-dimensional parameter (L/R) .

\subsubsection{Torsion}

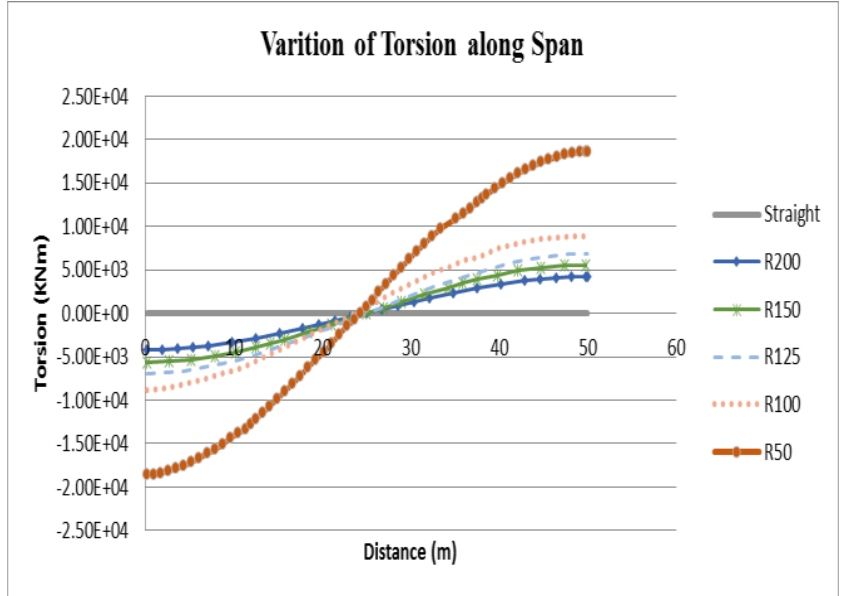

Figure 4: Variation of Torsion along Span 


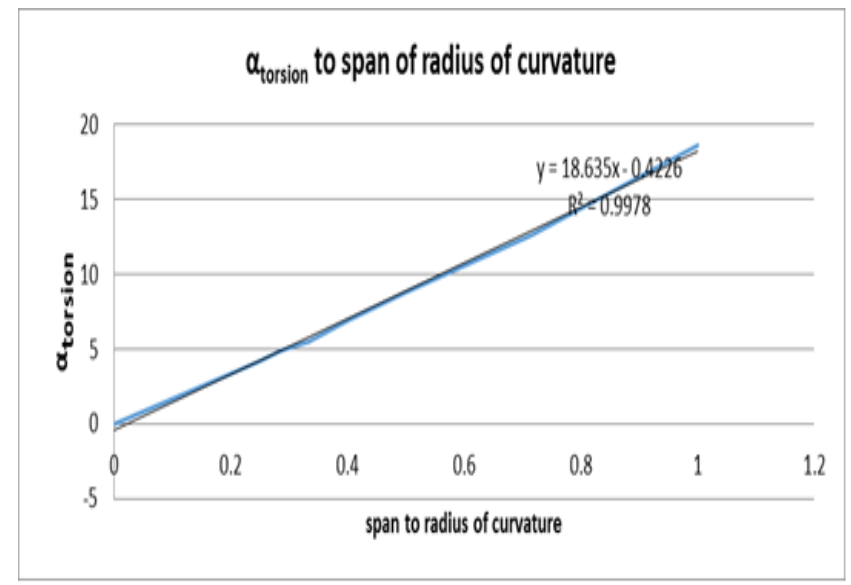

Figure 5: $\alpha_{\text {torsion }}$ to span of radius of curvature

\subsubsection{Bending Moment along the span}

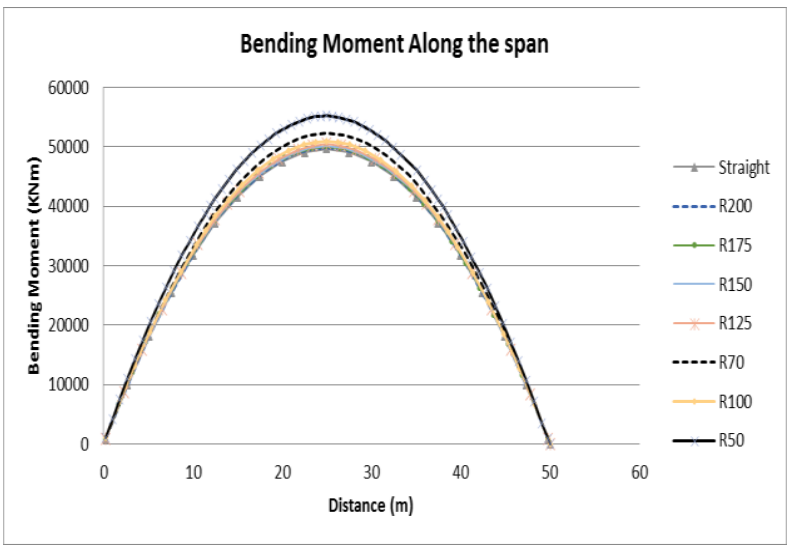

Figure 6: Bending Moment along the Span

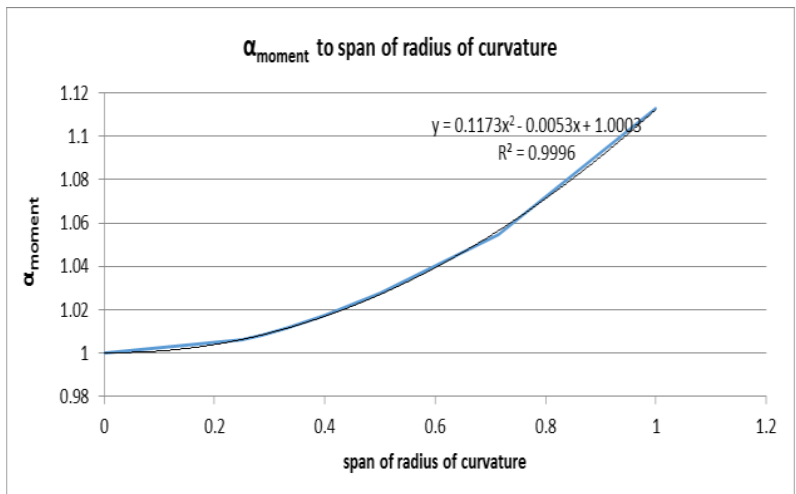

Figure 7: $\alpha_{\text {moment }}$ to span of radius of curvature

\subsubsection{Deflection along the span}

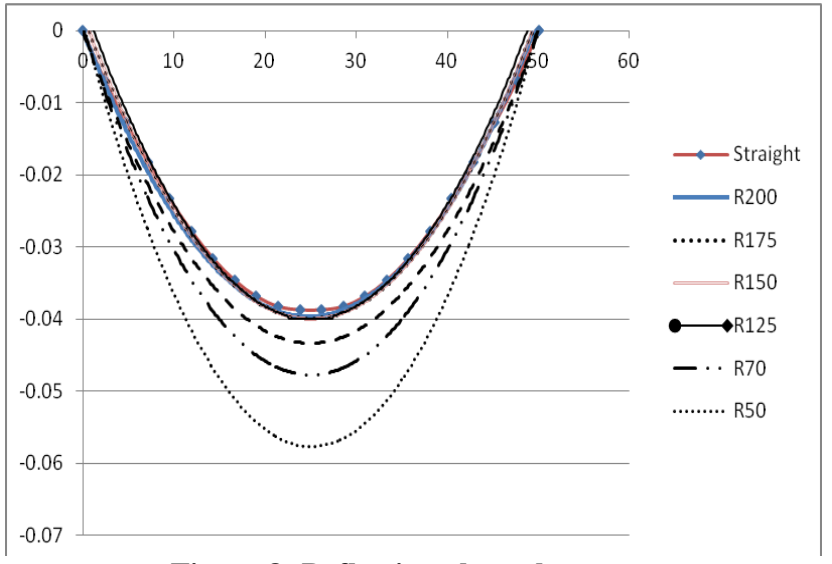

Figure 8: Deflection along the span

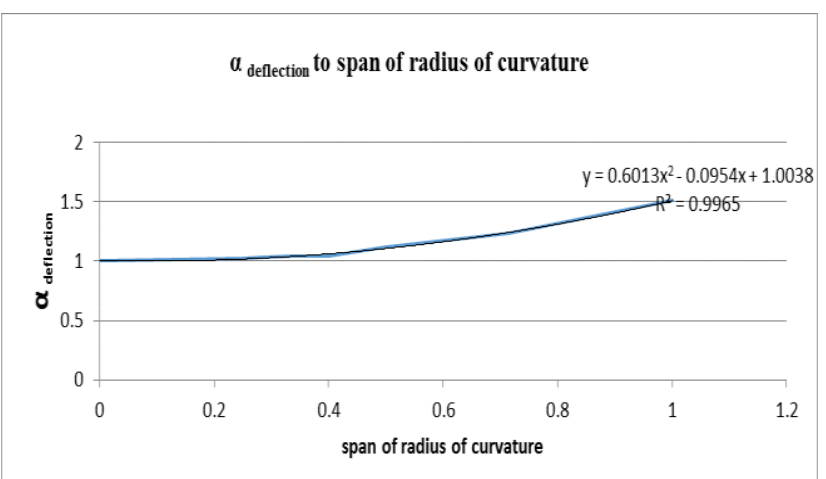

Figure 9: $\alpha_{\text {deflection }}$ to span of radius of curvature

\subsubsection{Top Longitudinal Stress at center of the Bridge}

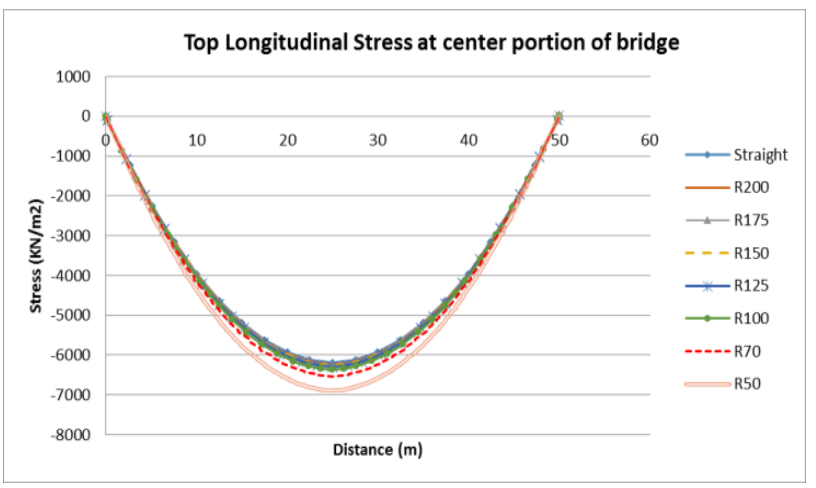

Figure 10: Top Longitudinal Stress at Center of Bridge 


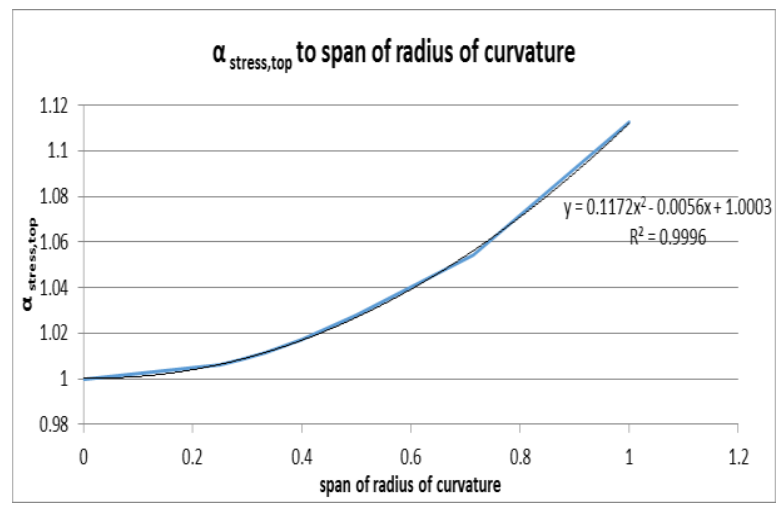

Figure 11: $\alpha_{\text {top longitudinal stress }}$ to span of radius of curvature

\subsubsection{Bottom Longitudinal Stress at center}

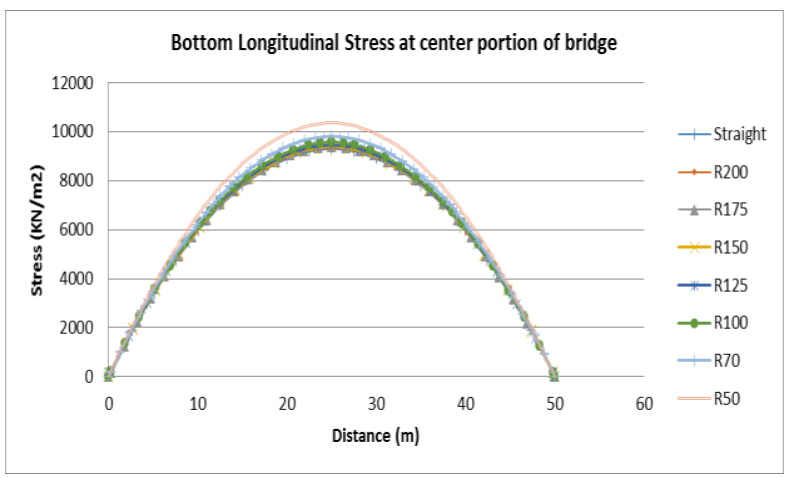

Figure 12: Bottom Longitudinal Stress at Center of Bridge

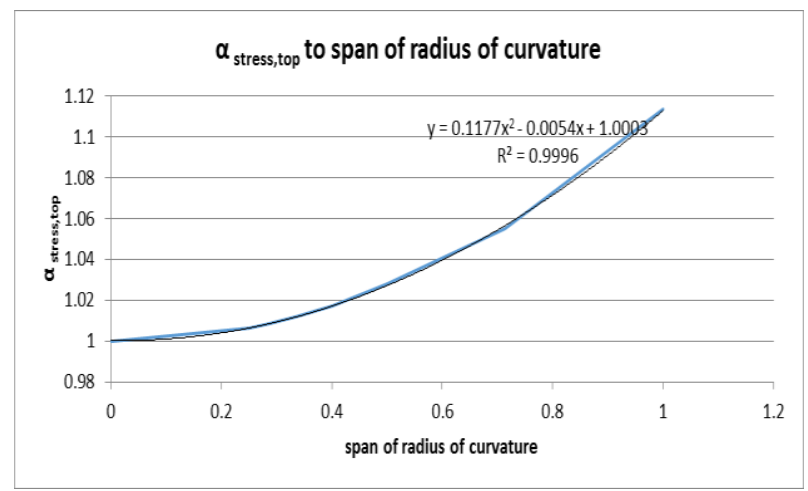

Figure 13: $\alpha_{\text {bottom longitudinal stress }}$ to span of radius of curvature

\subsection{Results of Time History Analysis}

Torsion, Bending moment about vertical axis (M22) and vertical shear for all eight bridge models were observed at support (At $0 \mathrm{~m})$ only. Similarly Bending Moment about horizontal axis is observed at mid span of bridge.

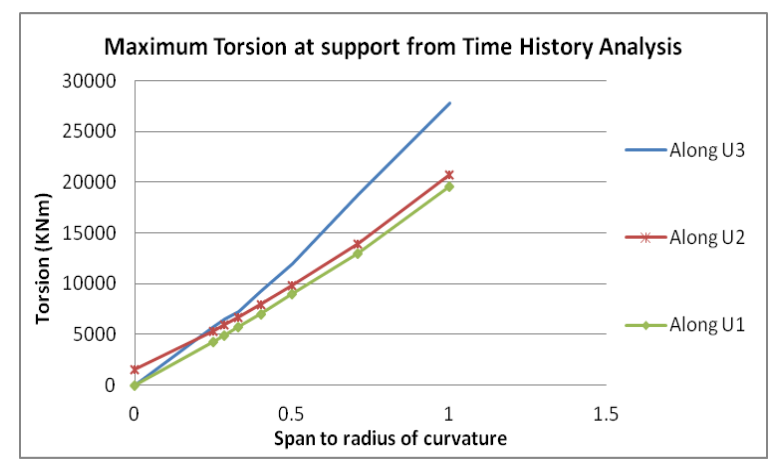

Figure 44: Maximum Torsion at Support from TH Analysis

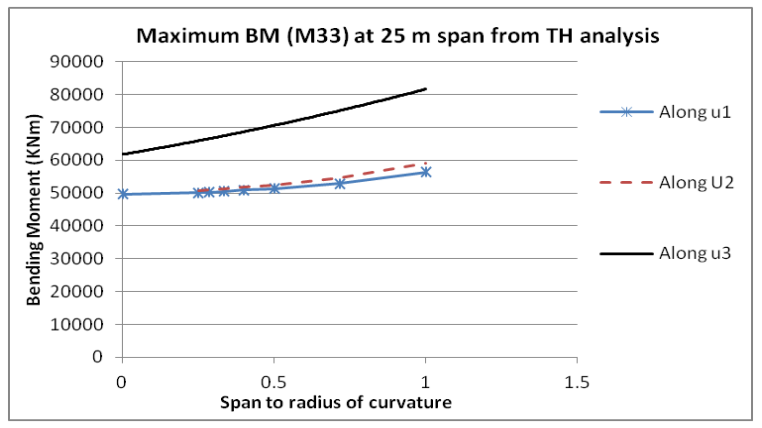

Figure 55: Maximum BM(M33) from TH Analysis

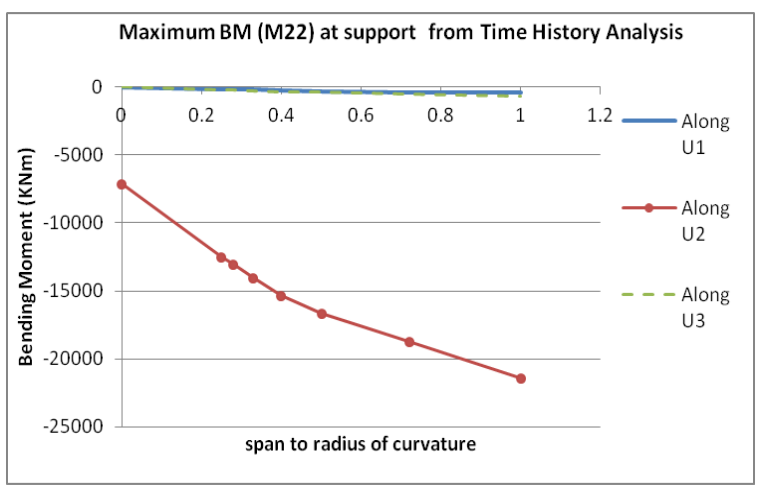

Figure 66: Maximum BM(M22) from TH Analysis

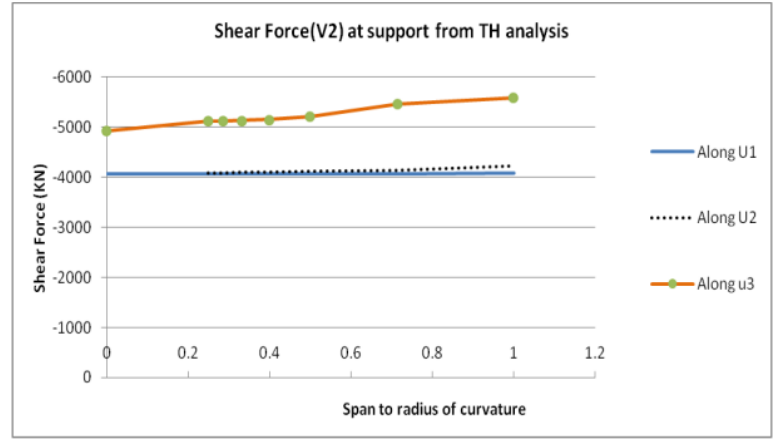

Figure 77: Shear Force at Support from TH Analysis 


\section{CONCLUSION}

From static analysis a multiplication factor for Torsion, Bending Moment, Shear and Longitudinal Stress is determined in terms of $\mathrm{L} / \mathrm{R}$ ratio, which when multiplied with response of straight bridge preliminary guideline for response of Curve Bridge. From Static analysis of (DL+LL+pre-stressed) load, as radius curvature increases, torsional moment also increases almost linearly which can be approximately related by multiplication factor which is, $\alpha$ torsion $=18.635 \mathrm{~L} / \mathrm{R}-0.4226$

- From Static Analysis of (DL+LL+Pre-stressed) load, when radius of curvature increases longitudinal Bending Moment increases non linearly which can be given by multiplying bending moment of straight with multiplication factor which is

$$
\alpha_{\text {bending }}=0.1173(\mathrm{~L} / \mathrm{R})^{2}-0.0053(\mathrm{~L} / \mathrm{R})+1.0003
$$

- From static analysis we can conclude that similar to longitudinal bending moment for small radius of curvature i.e. up to R125 deflection of box girder is almost same as that of straight bridge but it rises rapidly at R100.Deflection of R50 is almost $45 \%$ more than that of straight bridge. Relation of deflection of box girder in terms of span to radius of curvature can be given roughly by

$$
\alpha_{\text {deflection }}=0.6013 \mathrm{x}(\mathrm{L} / \mathrm{R})^{2}-0.0954 \mathrm{x}(\mathrm{L} / \mathrm{R})+1.0038
$$

- Longitudinal stress at top and bottom of the bridge increases as radius of curvature increases. Rate of increase of stress is small up to small radius of curvature but it rises rapidly as curvature increases. When the ratio of span and curvature is more than 0.5 stresses rises steeply.

- In all eight bridge models longitudinal stress at bottom is greater than that of longitudinal stress at top. With increase in curvature bottom and top longitudinal stresses changes almost equally, hence can be represented by same multiplication factor which is

$$
\alpha_{\text {stress }}=-0.1172 \mathrm{x}(\mathrm{L} / \mathrm{R})^{2}-0.0056 \mathrm{x}(\mathrm{L} / \mathrm{R})+1.0003
$$

- From Time History Analysis it can be concluded that when earthquake is applied along longitudinal direction torsion remain same as that of static load case. However torsion become more significant when transverse and vertical direction of earthquake load is applied. In higher curvature torsion due to vertical component is much higher than torsion due to transverse component of earthquake. But when curvature is torsion due to vertical and transverse component is almost same.

- Similar to Torsion Longitudinal Bending Moment about horizontal axis does not increase when earthquake load is applied along longitudinal direction. When earthquake load is applied along transverse direction there is slight increase in Bending Moment. Longitudinal Bending Moment about vertical axis is negligible when earthquake load is applied along longitudinal and vertical direction. But it is much significant when earthquake load is applied along transverse direction.
- Vertical Shear Force does not increase when earthquake load is applied along longitudinal direction. When earthquake load is applied along transverse direction there is slight increase in vertical Shear Force. Vertical Shear Force is most critical on vertical earthquake load. It increases rapidly with increase in span to radius of curvature.

\section{RECOMMENDATIONS}

Scope of the study can be increased with the following recommendation and extended works.

- In this thesis only the $50 \mathrm{~m}$ span of bridge section designed by Department of Road is used. For more generalized conclusion the all purposed span of the bridge should be modeled with varying section.

- The modeling of bridge abutment is idealized in this thesis work. It is strongly recommended to prepare three dimensional finite element model of the abutment and analyze correspondingly.

- For the analysis the number of ground motion plays a vital role. It is recommended to use more ground motion to have a proper outcome from the analysis.

- In future works, it is recommended to find out the material properties of existing study bridges and analyze correspondingly.

\section{ACKNOWLEDGEMET}

I would like to express my deepest gratitude to Department Structural Engineering Faculty of Institute of Engineering, Pulchowk Campus for valuable suggestions, helpful guidance and encouragement for the Thesis.

\section{REFERENCES}

[1] Cagri Ozgur (2007) "Behavior and Analysis of a Horizontally Curved and Skewed I-girder bridge" for MSc, School of Civil and Environmental Engineering

[2] Chu, K. J, and Pinjarkar, S. G. (1971) "Analysis of Horizontally Curved Box-Girder Bridges" Journal of the Structural Division ASCE 97(10), 2481-2501

[3] IRC: 6-2000, Standard Specifications and Code of Practice for Road Bridges, Section II, Loads and Stresses, The Indian Roads Congress, 2000.

[4] Martin Alenius (2003) "Finite Element Modelling of Composite Bridge Stability" MSc. Thesis, Department of Mechanics., Royale Institute of Technology.

[5] Subjected to Earthquake Loading" Journal of Civil Engineering and Architecture, Volume 6, No. 11

[6] P.K. Gupta, K K Singh and A. Mishra, (2010) "Parametric study on behavior of box-girder bridges using finite element method" Asian journal of civil engineering (building and housing) vol. 11,Pages-135-148.

[7] SAP2000, Integrated Software for Structural Analysis and Design

[8] Zakia Begum, (2010) "Analysis and behavior investigations of box girder bridges." MSc. Graduate School of Maryland. 